\title{
Effect of a System Air Conditioner on Local Air Quality in a Four-bed Ward
}

Aerosol and Air Quality Research

\section{OPEN ACCESS}

Received: August 26, 2020

Revised: December 2, 2020

Accepted: December 28, 2020

\section{${ }^{*}$ Corresponding Author:} ysjnuri@hanyang.ac.kr

\section{Publisher:}

Taiwan Association for Aerosol Research

ISSN: $1680-8584$ print ISSN: 2071-1409 online

\section{Copyright: The Author(s).} This is an open access article distributed under the terms of the Creative Commons Attribution License (CC BY 4.0), which permits unrestricted use, distribution, and reproduction in any medium, provided the original author and source are cited.

\author{
Jungsuk Lee ${ }^{1}$, Jung-Hun Noh ${ }^{1,2}$, Kwang-Chul Noh ${ }^{3}$, Young-Won Kim ${ }^{4}$, \\ Se-Jin Yook ${ }^{1 *}$ \\ ${ }^{1}$ School of Mechanical Engineering, Hanyang University, Seoul 04763, Korea \\ ${ }^{2}$ R\&D Center for Research and Business Cooperation Mechatronics Team, Institute for \\ Advanced Engineering, Yongin 17180, Korea \\ ${ }^{3}$ Air Lab, Gwangju 61478, Korea \\ ${ }^{4}$ International Research Center for Geothermal Energy, Korea Institute of Industrial Technology, \\ Gwangju 61012, Korea
}

\section{ABSTRACT}

In a ward where many patients are hospitalized, effective ventilation is important because airborne viruses may cause secondary infection. This study investigates the changes in the air quality in a four-bed ward according to the use of a ventilation system (VS), an air cleaner (AC), a system air conditioner (SAC), and personal curtains. The age of air was obtained both experimentally and numerically, and used as an indicator for the ventilation efficiency assessment. Consequently, the air flows from the outlets of the four-way cassette SAC could interfere with or contribute to the introduction of fresh air depending on the positions in the ward. For positions where the fresh air could not reach easily when only the VS was used, the air quality was improved by the additional use of the SAC. While the use of personal curtains prepared for each bed interfered with the air flow in the ward and resulted in local spots with poor air quality, the operation of both the VS and the SAC enhanced the air flow and improved the local air quality. The overall indoor air quality was improved when the $A C$ was used. However, the ventilation efficiency was reduced when the SAC was operated along with the $A C$, and the air quality deteriorated at positions where the flow caused by the SAC and that by the AC interfered with each other.

Keywords: Indoor air quality, Age of air, System air conditioner, Ventilation system, Air cleaner

\section{INTRODUCTION}

Most patients in need of long-term treatment are hospitalized. If some of the hospitalized patients are infectious virus carriers, secondary infection may occur to other patients in the ward because of airborne viruses (Beggs, 2003). Effective ventilation is important in reducing the possibility of such airborne infection. In aspect of energy saving, many studies on natural ventilation in hospital wards have been performed. Qian et al. (2010) conducted field tests to investigate natural ventilation for reducing airborne infection in hospital wards. They found that the air change rate reached up to 69 air changes per hour $(\mathrm{ACH})$ and thus concluded that natural ventilation could reduce cross-infection of airborne diseases. Adamu et al. (2012) evaluated four natural ventilation strategies for a single-bed hospital ward. They found that ceiling-based natural ventilation was helpful for enhancing air quality at isolated parts of the ward. Gilkeson et al. (2013) investigated local ventilation rates by applying a pulse-injection gas tracer method to assess potential infection risk in large naturally ventilated hospital wards. They found that indoor ventilation rates in a cross-ventilated ward increased with local external wind speed, leading to 3.4-6.5 ACH.

If air pollution outside the hospital is severe, natural ventilation has potential risk of exposing patients to other harmful aerosols. In this case, forced ventilation with the aid of particle removal 
systems needs to be considered in the places where ambient particulate matter (PM) concentration is high. Ventilation systems (VS) are used to supply fresh air into indoor environments and discharge the indoor air to the outside. Air cleaners (AC) are used to remove PM and enhance the indoor air quality. Therefore, many studies on indoor air quality have been conducted according to the use of the VS and/or AC. Rim and Novoselac (2010) measured the decay of indoor PM concentration according to the flowrate of VS. Villafruela et al. (2013) observed the change of indoor PM concentration according to the positions of the inlets and outlets of VS. Lee and Awbi (2004) analysed the ventilation efficiency of a room equipped with VS and partitioning walls. Zhuang et al. (2014) investigated the ventilation efficiency of an office equipped with VS, by changing the arrangement of the office furniture and the positions of the inlets and outlets of VS. Noh and Oh (2015) conducted a study to compare the air purification capabilities of AC in chambers of different sizes. Zuraimi et al. (2011) evaluated the performance of various types of portable $A C$ in removing influenza particles in residential environments. Noh and Yook (2016) investigated the influences of VS and AC on the air quality in a small lecture room. Noh et al. (2018) examined the effects of hospital ward curtains on the ventilation efficiency of a ward equipped with VS and AC.

Air conditioning systems, including system air conditioners (SAC) capable of both cooling and heating, can be used together with the VS in order to maintain the appropriate indoor temperature. Many studies on the indoor air quality according to air conditioning system have been conducted. Jung et al. (2015) investigated the distributions of indoor air pollutants at various locations in hospitals and analysed the relation between indoor air pollutant concentration and type of air conditioning systems. Asif et al. (2018) assessed indoor air quality levels in classrooms of four educational institute buildings with different ventilation and air conditioning systems. Jang et al. (2005) studied the relationship between $\mathrm{CO}_{2}$ concentration and air age according to flow rate and discharge angle of an SAC in a lecture room. Han et al. (2005) studied ventilation effectiveness for a lecture room equipped with a VS according to the discharge flow rate of an SAC or a fan coil unit. However, if more than two air-blowing units are used indoors, the air flow from the air conditioning unit can interfere with or contribute to the introduction of fresh air from VS and/or AC, depending on their positions in the indoor environments. However, not many studies have investigated the interfering or synergistic effects of air flows generated by these airblowing units.

The doors of wards are closed in many cases to promote the psychological stability of patients or block the spread of airborne viruses; hence, the air quality improvement in closed wards is required, and studies on the changes in the indoor air quality caused by the flow generation devices, such as VS, AC, and SAC, used for this purpose are necessary. In addition, curtains are used in wards to protect the privacy of patients. The use of curtains may significantly affect the indoor air flow (Noh et al., 2018). However, few studies have been conducted on the indoor air quality according to the use of the VS, AC, and SAC considering such special situations of wards. Therefore, in this study, the effects of the VS, AC, and SAC on the indoor air quality of a four-bed ward were observed according to the use of curtains. The age of air can be used as an indicator for comparing the indoor air quality (Parra et al., 2006; Wang et al., 2008; Tung et al., 2010). In this study, the age of air was obtained both experimentally and numerically, and the local values of the age of air at various positions inside the ward, including the position of each bed, were compared.

\section{EXPERIMENTAL METHOD}

Fig. 1 shows the photograph and the schematic diagram of the laboratory used to simulate a four-bed ward equipped with a ventilation system (VS), an air cleaner (AC), a system air conditioner $(S A C)$, and curtains. The laboratory had dimensions $(\mathrm{W} \times \mathrm{D} \times \mathrm{H})$ of $8.3 \mathrm{~m} \times 5.0 \mathrm{~m} \times$ $2.85 \mathrm{~m}$, and a volume of approximately $118.3 \mathrm{~m}^{3}$. Four hospital beds were present in the laboratory, and curtains were installed for each bed. It is common that the headboard faces the wall with both sides of the ward bed exposed. However, due to the limited space in the laboratory, each ward bed was up against the wall on one side. As for the VS, two inlet ducts and two outlet ducts were installed on the ceiling right above the beds. The bed at position II was 
(a)

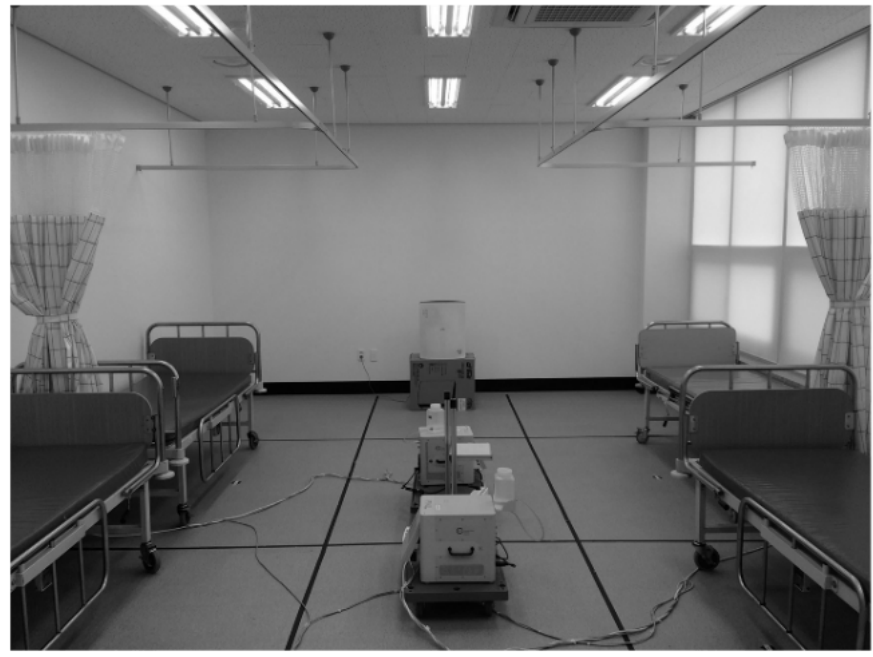

(b)

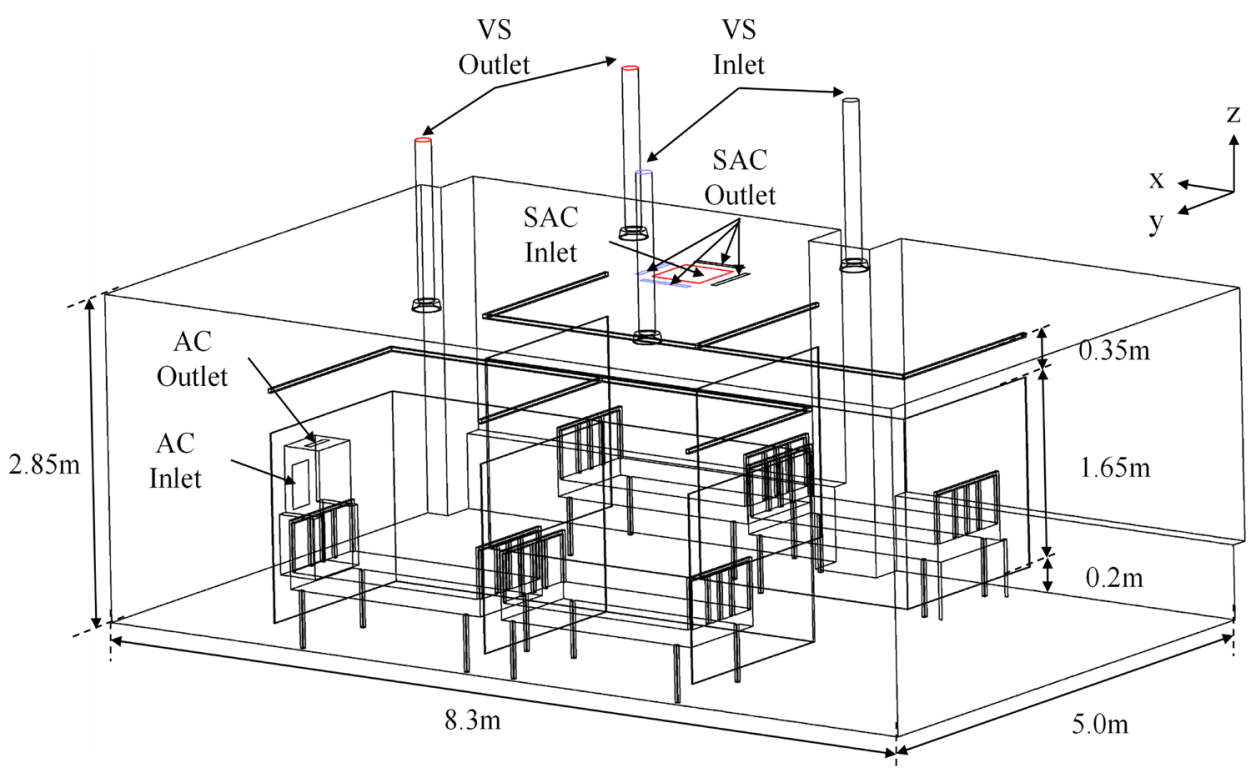

(c)

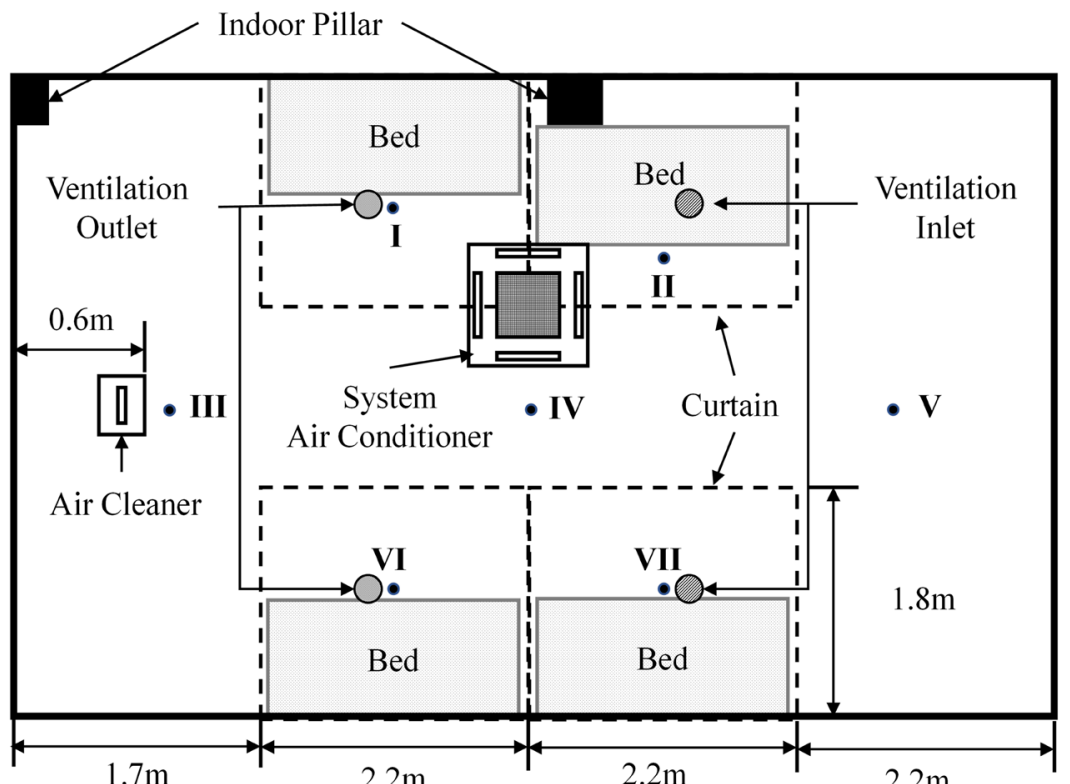

Fig. 1. Laboratory used to simulate a four-bed ward equipped with the VS, AC, SAC, and curtains (a) photographs (b) isometric view (c) plane view. 
apart from the wall because of a protruded column on the wall, but the three beds at positions $\mathrm{I}, \mathrm{VI}$, and VII were closely positioned to the walls. The clean air that went through the HEPA filter was supplied into the laboratory through the inlet ducts of the VS. A four-way cassette SAC was installed on the ceiling in a position slightly biased to one side from the center of the four inlet and outlet ducts of the VS. The filter of the pre-filter grade was installed in the SAC, and its particle removal capability was very low. The SAC played the role of just circulating the air in the laboratory with air-conditioning. The AC was installed slightly apart from the wall near the outlet ducts of the VS and sucked in the air in a direction parallel to the wall, then discharged it toward the ceiling. The air flow rates of the VS and the AC were $300 \mathrm{~m}^{3} \mathrm{~h}^{-1}$ and $350 \mathrm{~m}^{3} \mathrm{~h}^{-1}$, respectively. The flow rates at the inlet and the outlet of each device were the same. Especially, the flow rate of air introduced into the laboratory from the VS inlet ducts was almost the same as that drawn by the VS outlet ducts. Therefore, it was assumed that the pressure difference between the inside and the outside of the laboratory was low enough to neglect any additional air flow through narrow gap around the laboratory door. The laboratory had been initially designed based on the ANSI/ASHRAE/ASHE Standard 170-2008 for ventilation of health care facilities, that is, to have the number of air changes per hour as 6 . However, from the measured flow rate of the VS installed in the laboratory, the number of air changes was estimated to be 5.1, which was slightly lower than the requirement for hospital wards. Meanwhile, the air flow rate sucked in by the SAC was $1000 \mathrm{~m}^{3} \mathrm{~h}^{-1}$, while that of $250 \mathrm{~m}^{3} \mathrm{~h}^{-1}$ was discharged from each of the four outlets. The discharge angles of the SAC outlets were $30^{\circ}$ from the direction parallel to the ceiling. As shown in Table 1, the experiment was conducted for a total of eight cases according to the use of the SAC, AC, and curtains while the VS operated all the time.

The particle number concentration in the air was measured at seven positions, i.e., I-VII, using condensation particle counters (CPC; Model CPC-0701, HCT Co., Ltd., Republic of Korea). The CPCs used in this study can measure particle number concentrations up to $10^{5} \mathrm{~cm}^{-3}$, with $50 \%$ detection efficiency at $7 \mathrm{~nm}$ and $95 \%$ detection efficiency at $15 \mathrm{~nm}$. The opening of the sampling probe connected to the CPC was $0.85 \mathrm{~m}$ above the floor. The sampling line was vertically installed such that the particle transport loss caused by gravitational settling could be minimized. The sizes of exhaled particles are known to be mostly in submicron range with the size distribution peaks at about $0.07 \mu \mathrm{m}$ during tidal breathing and 0.2-0.5 $\mu \mathrm{m}$ during airway closure (Holmgren et al., 2010). Since the incense burning is known to produce submicron particles with the peak diameter in the range approximately from 90 to $200 \mathrm{~nm}$ depending on the product (Chang et al., 2007; See et al., 2007; Ji et al., 2010), we decided to generate particles by incense burning to simulate the exhaled particles from patients. With all the windows and doors of the laboratory closed, the incense burning was performed in the middle of the laboratory for more than $10 \mathrm{~min}$. After the incense was extinguished, an electric fan was operated for 20 minutes to stir air in the laboratory, and then particle concentration monitoring started. The air flow in the laboratory was then stabilized for more than 20 min, such that the initial particle number concentration could be uniform in the laboratory at above $10^{4} \mathrm{~cm}^{-3}$ as shown in Fig. 2, which displays an example of particle concentration monitoring results obtained during experiment. After 20 minutes of stabilization, the VS, AC, and/or SAC were turned on. As a result, the particle number concentration decayed exponentially as illustrated in Fig. 2. The experiment was conducted three times for each case to secure repeatability.

Table 1. Experimental and numerical cases according to the use of the VS, SAC, AC, and curtains.

\begin{tabular}{lllll}
\hline Case & Ventilation System & System Air Conditioner & Air Cleaner & Curtain \\
\hline A & On & Off & Off & Not used (folded) \\
B & & Off & Used (unfolded) \\
C & & On & Not used (folded) \\
D & & Used (unfolded) \\
E & & On & On & Not used (folded) \\
F & & Off & Used (unfolded) \\
G & & & Off & Not used (folded) \\
H & & & On & Used (unfolded) \\
\hline
\end{tabular}




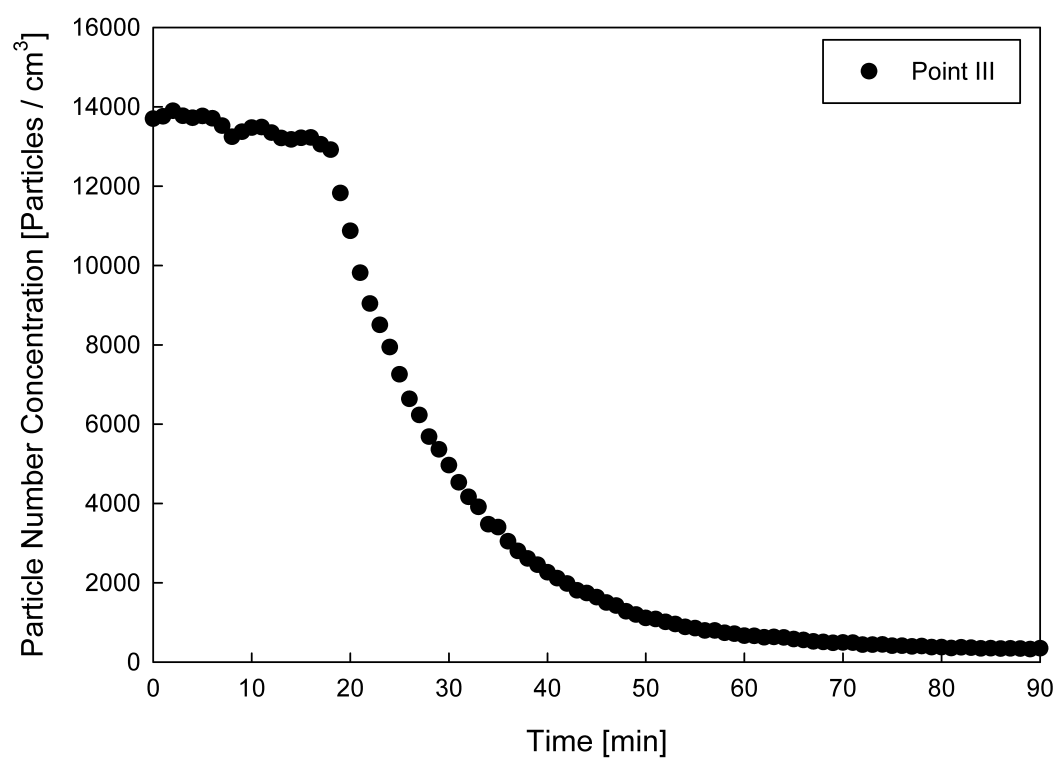

Fig. 2. An example of particle concentration monitoring results obtained during experiment.

The age of air was calculated through the curve fitting of the particle number concentration data measured over time as shown in Eq. (1):

$C=C_{0}+A \exp \left(-\frac{t}{\tau}\right)$

where $t$ is time; $C$ is the particle number concentration at time $t ; C_{0}$ is the particle number concentration that converged after a long period of time; $A$ is the initial particle number concentration; and $\tau$ is the age of air which represents the time it takes for the introduced clean air to reach a certain position. As can be seen from Eq. (1), the lower age of air indicates a higher particle removal efficiency because the particle number concentration rapidly decreases, or it indicates a better ventilation efficiency because the clean air penetration is better. In other words, the introduction of clean air and the discharge of polluted air are more active.

\section{NUMERICAL METHOD}

A three-dimensional simulation was conducted on the four-bed ward shown in Fig. 1 to obtain the age of air through a numerical method. ANSYS FLUENT Release 16.1, a commercial CFD code, was used to analyze the indoor air flow. The air flow was assumed to be three-dimensional, steady, incompressible, and turbulent. The standard $k-\varepsilon$ model was used for the turbulent flow analysis, and the SIMPLE algorithm was used for the velocity and pressure coupling (Chen et al., 2011; Wu and Ahmed, 2012; Alajmi et al., 2015; Cheng and Lin, 2015; Kong et al., 2017). As depicted in Fig. 1(b), the velocity inlet boundary conditions were given to the two VS inlets, the AC outlet, and the four SAC outlets. Mean velocity of air injected into the laboratory was set at $3.92 \mathrm{~m} \mathrm{~s}^{-1}$ at each of the two VS inlets, $4.77 \mathrm{~m} \mathrm{~s}^{-1}$ at the AC outlet, and $1.62 \mathrm{~m} \mathrm{~s}^{-1}$ at each of the four SAC outlets. The air was discharged from the four SAC outlets with an angle of $30^{\circ}$ from the direction parallel to the ceiling. The pressure outlet boundary conditions of $101.3 \mathrm{kPa}$ were given to the two VS outlets, the AC inlet, and the SAC inlet. In order to simulate suction of air by each device, the mass flow rate of air exhausted through each of the two VS outlets was set at $0.074 \mathrm{~kg} \mathrm{~s}^{-1}$, that drawn into the AC inlet at $0.098 \mathrm{~kg} \mathrm{~s}^{-1}$, and that sucked into the SAC inlet at $0.198 \mathrm{~kg} \mathrm{~s}^{-1}$. Lastly, no-slip conditions were set on all the indoor walls, ceiling, floor, exterior of the AC, exterior of the SAC, beds, and curtains. Turbulent intensity was set at $5 \%$. Temperatures at the SAC inlet and the VS inlet were set at $15.5^{\circ} \mathrm{C}$ and $30^{\circ} \mathrm{C}$, respectively. Temperatures of the air and all walls in the laboratory were set constant at $30^{\circ} \mathrm{C}$. Considering the actual shapes of the ceiling diffusers 
used as the inlet and outlet ducts of the VS, a grid system was constructed using a tetrahedral mesh in the vicinity of the ceiling diffusers and a hexahedral mesh in the other areas, as shown in Fig. 3. Dense grids were generated near the ward beds and ceiling diffusers due to the complex shapes of them, while relatively coarse grids were used in other areas. Near-wall grids were generated to satisfy the condition of $0.8<y^{+}<5$, where $y^{+}$is the dimensionless wall distance, that is, the centroids of wall-adjacent grid cells were located within the log-law layer (ANSYS, Inc., 2009). Especially, grid spacing near the walls was constant as illustrated in a sub-figure of Fig. 3. As a result of conducting a grid independence test, the number of grids was determined to be approximately 12-14 million for each case.

The age of air was calculated using the following equations in addition to the flow analysis:

$$
\begin{aligned}
& \frac{\partial}{\partial x_{i}} \rho u_{i} \Phi-\vec{J} \frac{\partial \Phi}{\partial x_{i}}=\rho \\
& \vec{J}=-\left(\rho D_{m}+\rho D_{t}\right) \frac{\partial \Phi}{\partial x_{i}}
\end{aligned}
$$

where $\rho$ is the air density; $u_{i}$ is the air velocity; $\vec{J}$ is the diffusion term of the air; $D_{m}$ is the molecular diffusivity; $D_{t}$ is the turbulent diffusivity; and $\Phi$ is the age of air. The indoor air was sucked in by the four-way cassette SAC, and then discharged through the four air outlets; hence, a user-defined function (UDF) was created to set the age of air at the four air outlets as a passive scalar value. In other words, at every iteration step, the UDF first calculated the average of the air ages at all grids located on the air inlet of the SAC and then set this average value as the air ages at all grids located on the four air outlets of the SAC, by assuming that no particles could be collected by the SAC. To the contrary, high-performance filters were used in the VS and the AC. Thus, the age of air was assumed to be zero at the inlet ducts of the VS and the outlet of the AC assuming that particle-free air was supplied. The flux value of $\partial \Phi / \partial x_{i}$ was set to zero in the outlet of the VS and in the inlet of the AC to meet these conditions.

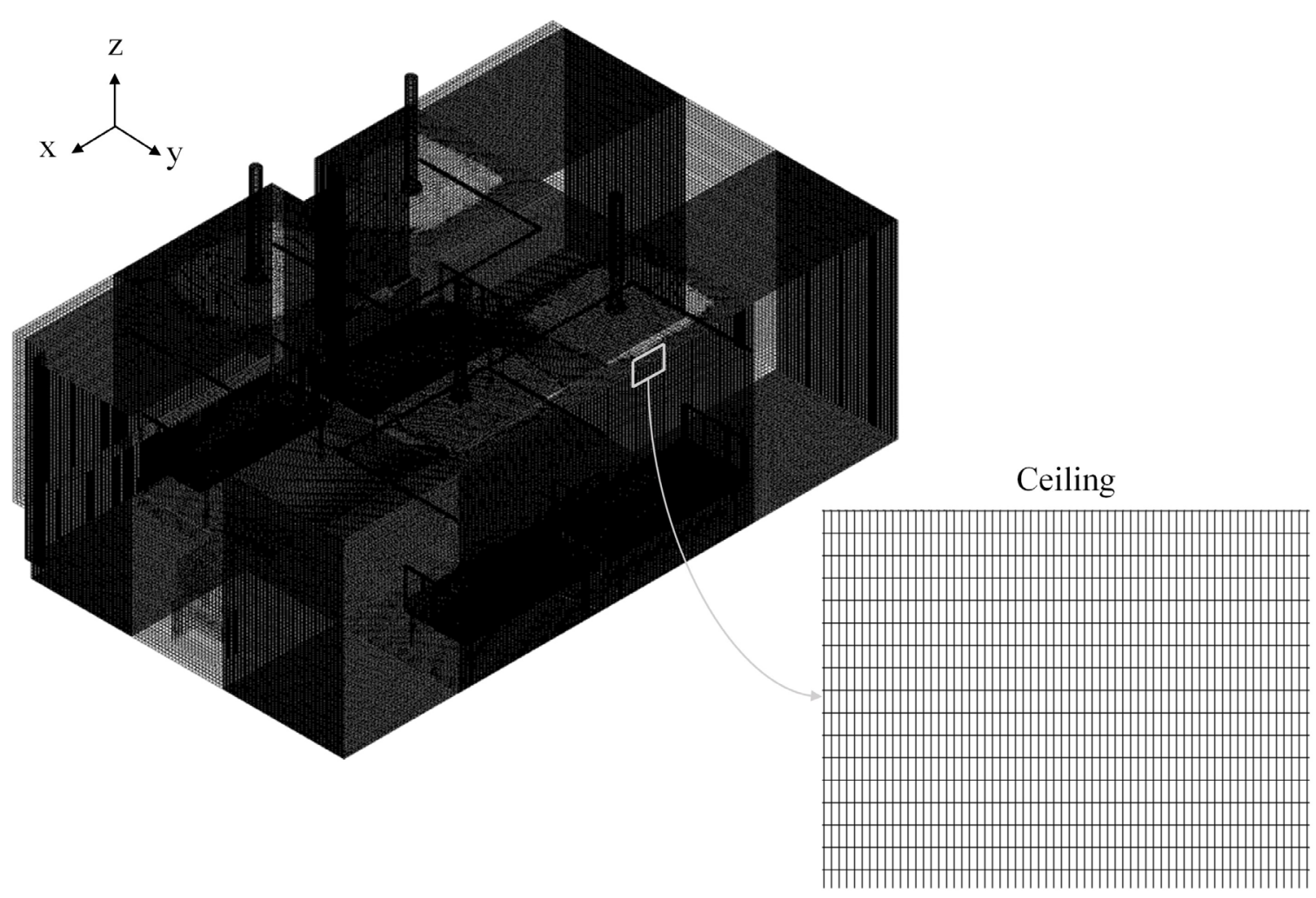

Fig. 3. Grid system for numerical simulation. 


\section{RESULTS AND DISCUSSION}

The changes in the air flow caused by the operation of the SAC significantly affected the indoor air quality depending on the positions. Fig. 4 shows the distribution of flow velocity, age of air, and temperature in the laboratory for Case $\mathrm{E}$ predicted by the numerical analysis. In other words, Fig. 4(a) displays velocity contour at specified planes, Fig. 4(b) velocity vectors on A-A' plane, Fig. 4(c) velocity vectors on B-B' plane, Fig. 4(d) air age contour, and Fig. 4(e) temperature contour. The flow velocity distribution indicated that the SAC sucked in the indoor air, and then discharged it in the same flow rate through each outlet. The air discharged from the SAC tended to mostly flow along the ceiling and descend in the vicinity of the side walls. The distribution of the age of air denoted that the indoor flow characteristics by the SAC were reflected well in the numerical

(a)
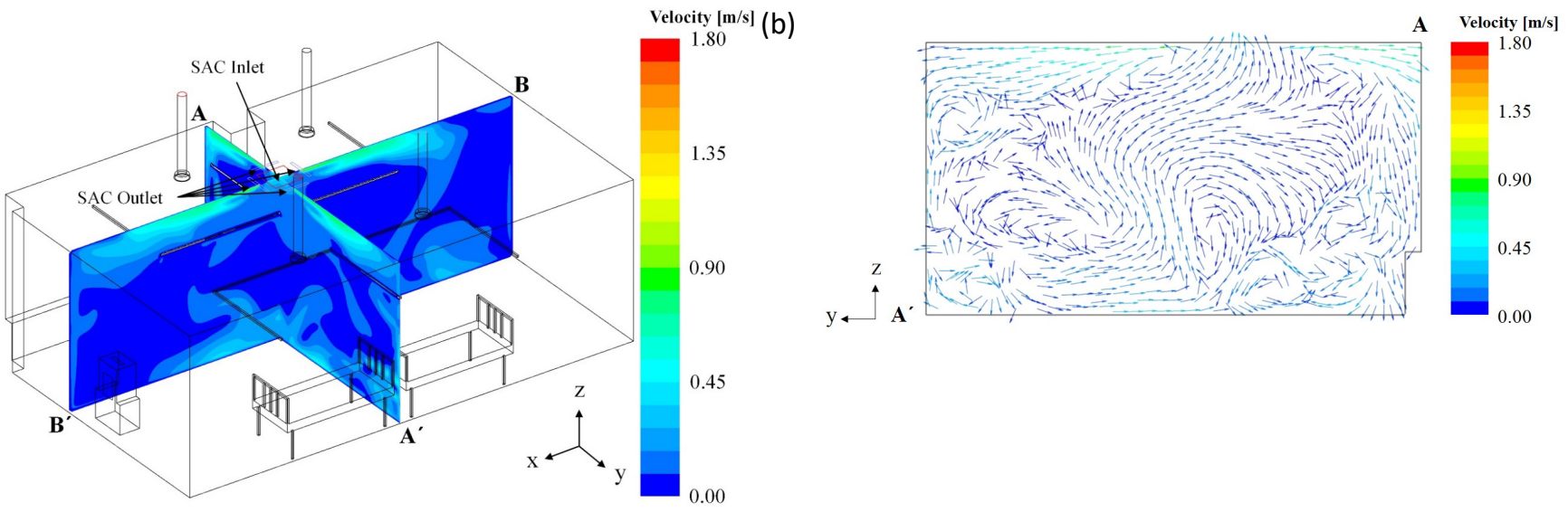

(c)

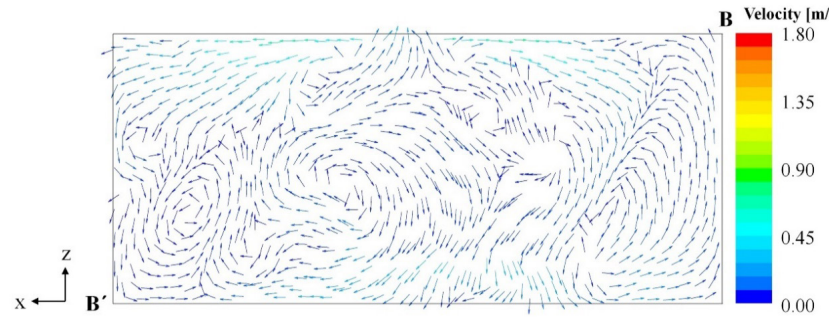

(d)

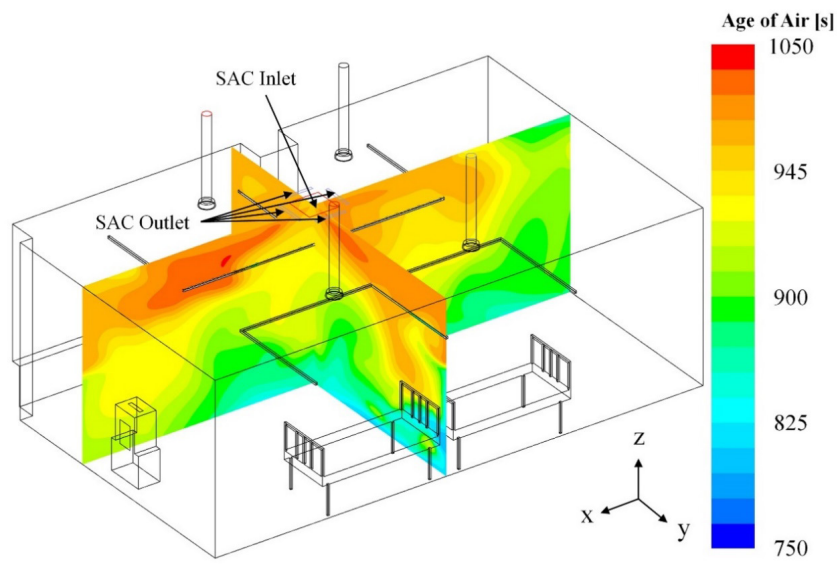

(e)

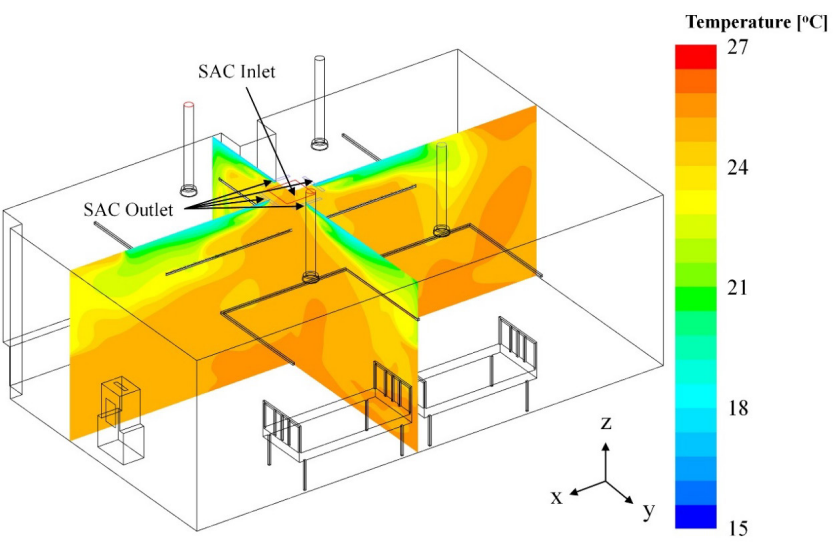

Fig. 4. Numerical results for Case $E$ (a) contour of distribution of flow velocity (b) flow velocity vector on yz-plane (c) flow velocity vector on xz-plane (d) distribution of age of air (e) distribution of temperature. 


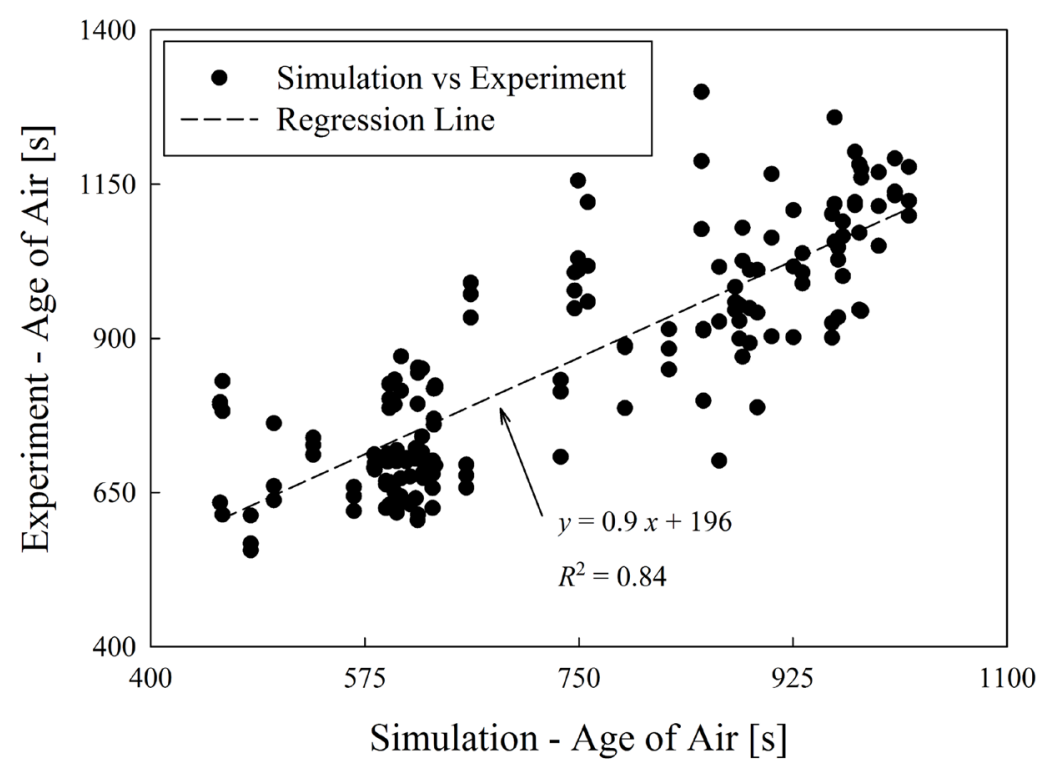

Fig. 5. Comparison of experimental data and numerical results.

analysis through the use of the UDF, which implemented the circulation of the air that passed through the low-quality filter with a very low collection efficiency. The age of air was generally low in areas where the direction of the air flow introduced to the laboratory through the inlet ducts of the VS was the same as that of the air flow discharged from the SAC. In contrast, the age of air was generally high in areas where the air flow was stagnant because the air sucked into the outlet duct of the VS interfered with the air flow discharged from the SAC. The cold air was discharged equally from the four outlets of the SAC and cooled down the air temperature in the laboratory.

The age of air was compared between numerical results and experimental data, as shown in Fig. 5. The number of numerical data was 56, since there were 8 cases and 7 measurement locations. The number of experimental data were 168, because experiments were repeated 3 times for each case. The slope of the regression line was 0.9 and the coefficient of determination was $R^{2}=0.84$, indicating that the numerical method used in this study can correctly predict the distribution of the age of air at measurement locations I through VII.

The distribution of clean air supplied from the VS could be greatly influenced by the flow generated by the SAC. Fig. 6(a) represents the distribution of the age of air at the height $(0.85 \mathrm{~m}$ from the floor) of the nose of a patient lying in the bed for Case E, in which the VS and the SAC were operated; the AC was turned off; and the curtains were not used. The asymmetric indoor flow was formed because the SAC was closer to positions I and II than to positions VI and VII. The age of air was generally low in the vicinity of the ventilation inlets, where clean air was introduced indoors, and high in the vicinity of the ventilation outlets. As the SAC sucked in the air through its large central area, a value similar to the average age of air was found in the area under the SAC. The age of air was lowest in the areas under the ventilation inlets, but their ranges were very narrow. The age of air in the vicinity of the ventilation inlets tended to be low in the regions close to the longer side walls whereas it was relatively high in the region close to the shorter side walls. The clean air supplied from the ventilation inlets was interrupted by the air flow discharged from the SAC, and as a result the region showing the air age of lower than about $1000 \mathrm{~s}$ appeared in the space surrounded by a virtual line connecting the positions I, II, V, VII, VI, and I. Interestingly, the region between the positions II and VII showed relatively high age of air, even though this region was very close to the ventilation inlets. The age of air appeared higher than about $1000 \mathrm{~s}$ near the shorter side wall around the position V, as the air discharged from the SAC in the direction toward the potion $V$ flowed along the ceiling and descended along the shorter side wall to form a large recirculation. The age of air in the vicinity of the ventilation outlets was generally high near the side walls because of the influence of the flow interference between the VS and the SAC. Especially, the age of air was higher than approximately $1025 \mathrm{~s}$ in the region between 
(a)

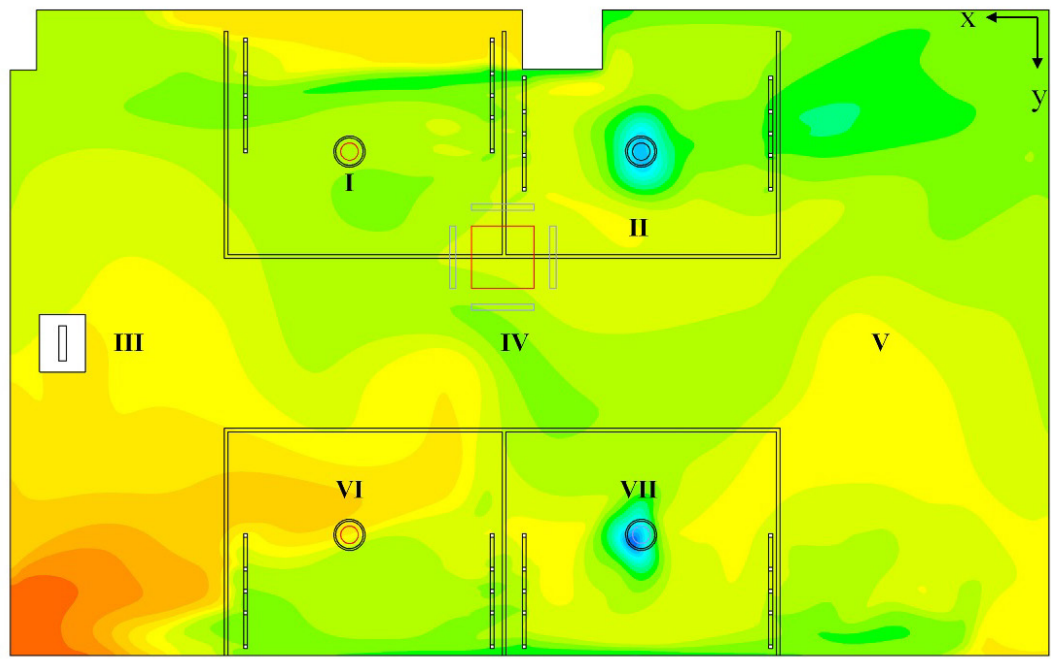

Age of Air [s]

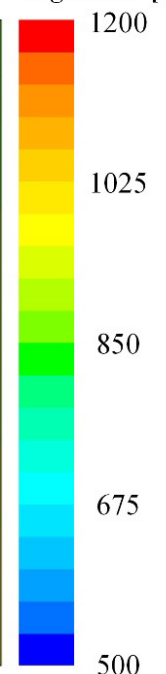

(b)

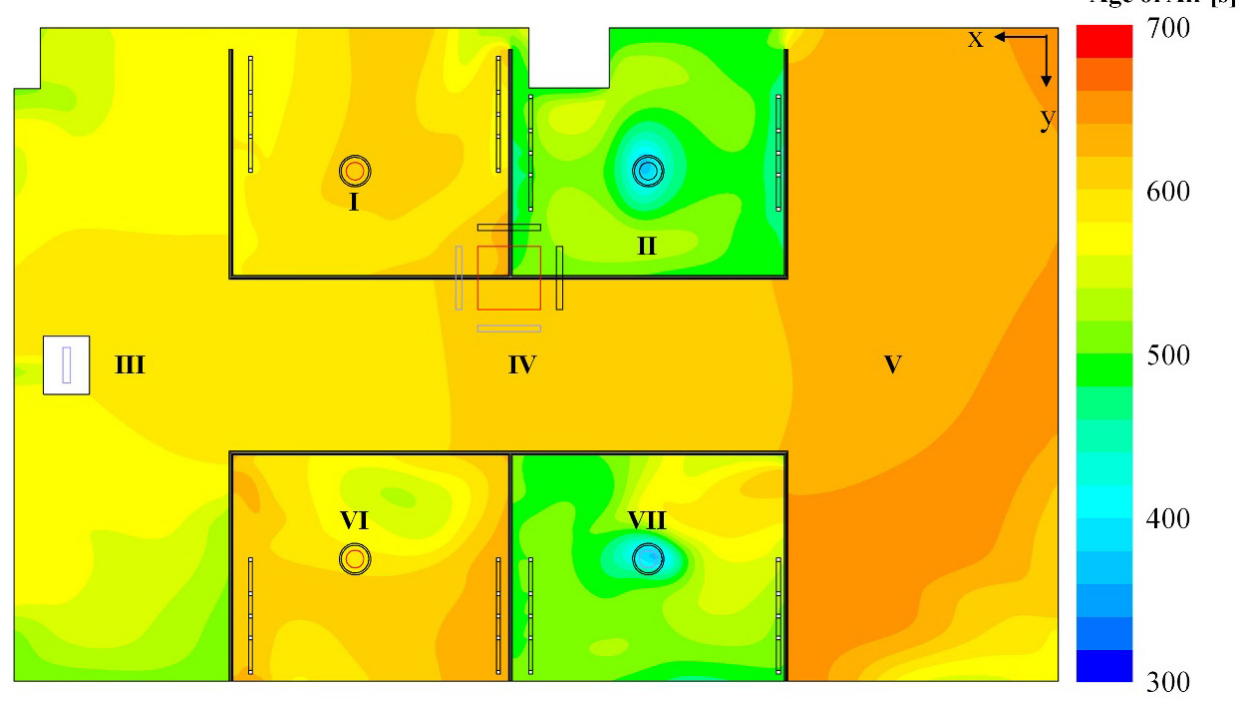

Fig. 6. Contour of age of air (a) Case E (b) Case H.

the positions III and VI. When the SAC is operated together with the VS as in Case E, it would be better to place the ward beds in the regions under the VS inlets, or the VS outlet which is close to the SAC.

The AC could greatly reduce the average particle concentration level in hospital wards equipped with the VS, especially at the regions where the flow is stagnant. Fig. $6(\mathrm{~b})$ shows the distribution of the age of air at the height $(0.85 \mathrm{~m}$ from the floor) of the nose of a patient lying in the bed for Case $\mathrm{H}$, in which the VS, SAC, and AC were operated, and every personal curtain was drawn. A comparison between Figs. $6(\mathrm{a})$ and $6(\mathrm{~b})$ shows that the overall internal air quality was improved, and the age of air was reduced by the additional operation of the AC. The installation of the $A C$ in the vicinity of position III, where the age of air was the highest, that is, more than $1000 \mathrm{~s}$, because of the severe stagnation of the air flow (as shown in Fig. 6(a)), significantly lowered the age of air in that position, that is, below $650 \mathrm{~s}$ (as shown in Fig. 6(b)). The age of air was the lowest in the patients' personal spaces at positions II and VII located under the ventilation inlets because of the use of personal curtains. In contrast, the age of air was relatively higher in the patients' personal spaces at positions I and VI located under the ventilation outlets, but was similar to the average age of air because the indoor air flow was improved by the use of the SAC and the AC. However, the age of air still appeared higher in the region near the position $\mathrm{V}$, compared to air ages in other regions, due to the fact that the flow of clean air discharged 
from the AC was interrupted by the flow generated by the SAC. However, the age of air at the position $\mathrm{V}$ appeared much reduced to about $650 \mathrm{~s}$ as shown in Fig. 6(b), compared to the value of about $950 \mathrm{~s}$ as shown in Fig. 6(a).

The SAC equipped with a filter of the pre-filter grade with a very low efficiency did not change the mean air quality much but did affect the local air quality. Fig. 7 presents the results of cases $A$ and $E$ and compares the air quality according to the operation of the SAC while the VS operated. In this case, the AC was turned off, and the curtains were not used. The air quality deteriorated in the vicinity of the ventilation inlets (positions II and V) because of the operation of the SAC. In other words, due to the use of the SAC, the experimentally obtained age of air at positions II and $\mathrm{V}$ increased by $2.4 \%$ and $5.3 \%$, respectively, while the numerically determined air ages were predicted to increase by $5.4 \%$ and $8.6 \%$, respectively. This result can be attributed to the SAC affecting the flow of the fresh air introduced through the ventilation inlets and the air with the relatively high age sucked in through the center of the SAC being discharged through the outlets and mixed with the fresh air. Meanwhile, the air quality was improved at position VII due to the use of the SAC, that is, the age of air from experiment was lowered by $10.4 \%$ and the air age from simulation was decreased by $1.4 \%$. This is because the air flow stagnation was solved by the flow, in which the air discharged from the SAC flowed along the ceiling and descended along the side walls, and the air with the relatively low age sucked in through the center of the SAC was discharged through the outlets and mixed with the polluted air. Regarding the air quality near the VS outlets, both experiment and simulation showed that the age of air decreased at position I while it increased at position VI. This is because the air flow discharged from the SAC delivered the fresh air from the VS inlet near position II to the position I while it interrupted the clean air supply from the VS inlet near position VII to the position VI. This means that the distance between the VS inlet/outlet and the SAC can greatly affect the local air quality. The average values of experimentally obtained air ages for the Cases $A$ and $E$ were $1033 \mathrm{~s}$ and $968 \mathrm{~s}$, respectively, while those of numerically determined air ages were $902 \mathrm{~s}$ and $914 \mathrm{~s}$, respectively.

The local indoor air quality could be greatly influenced by the use of the curtains in the ward equipped with the SAC. Fig. 8 shows the results of cases B and F and compares the air quality according to the operation of the SAC while the VS operated, and every curtain was drawn. The $A C$ was not operated in these cases. The age of air when the SAC was not operated was relatively lower at positions II and VII, which were close to the ventilation inlets, because the fresh air introduced through the ventilation inlets was stagnated in the spaces surrounded by the curtains. Meanwhile, the age of air was relatively higher at the other positions. Therefore, it is recommended

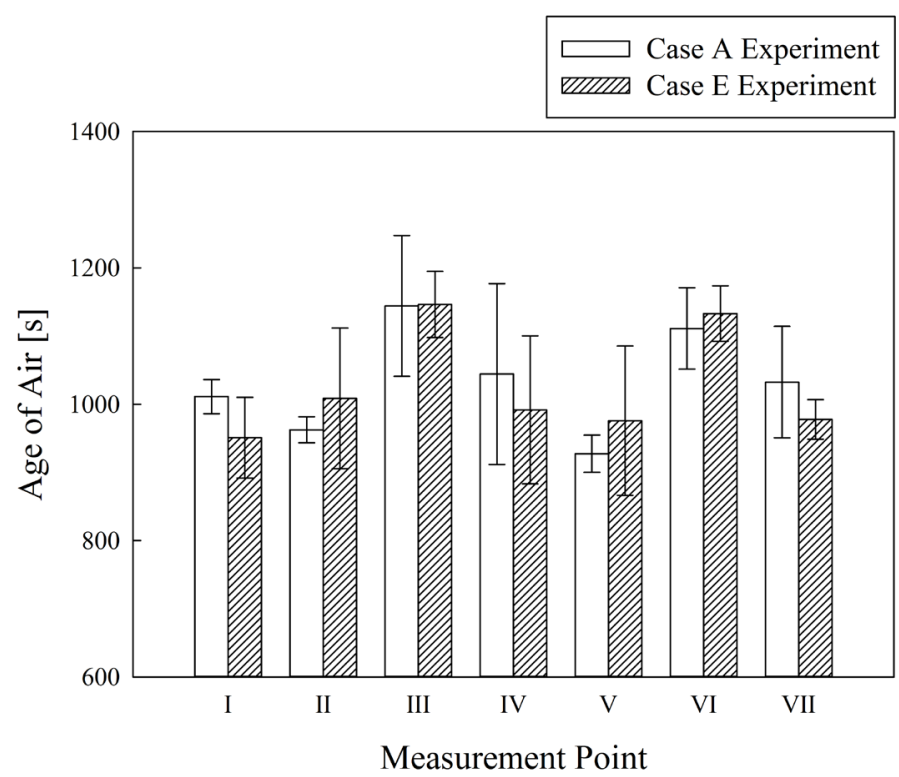

(a)

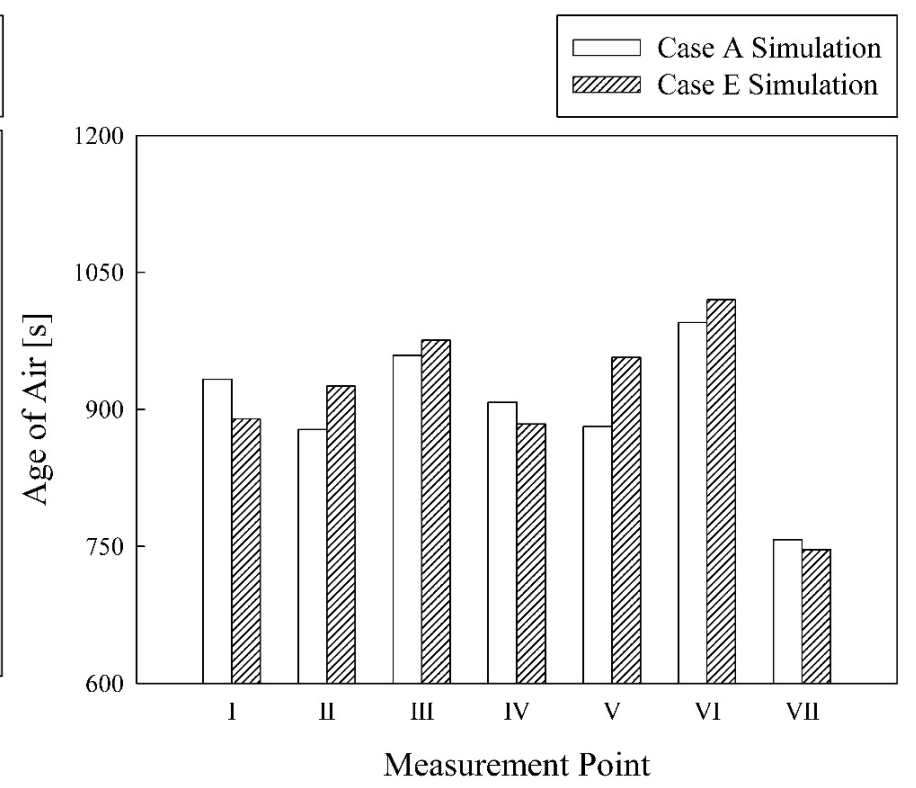

(b)

Fig. 7. Comparison of the age of air results between Case $A$ and Case $E(a)$ experimental data (b) numerical results. 


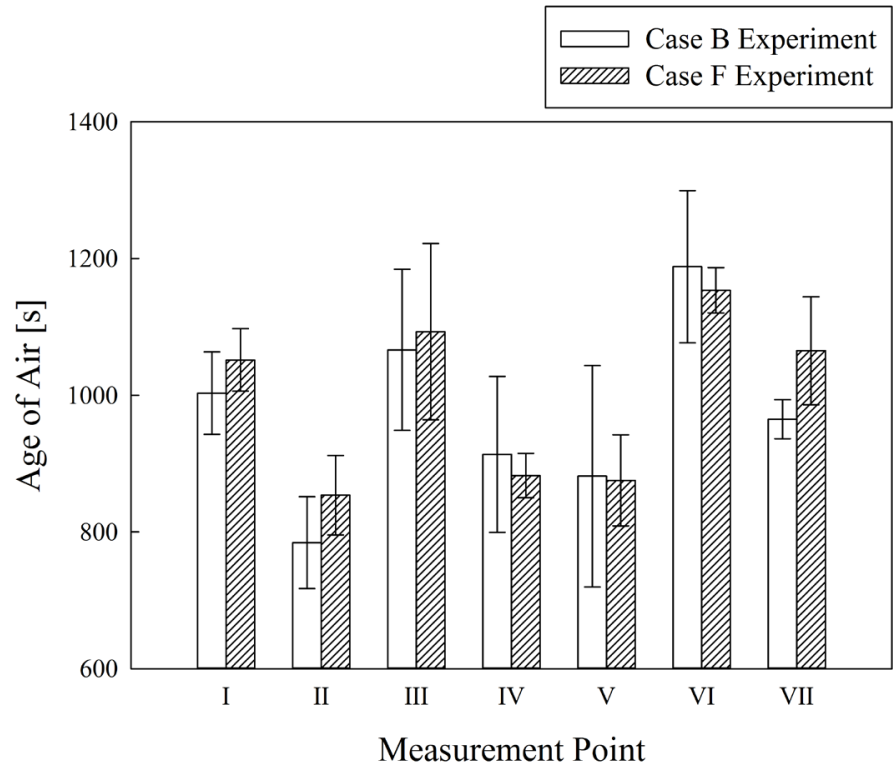

(a)

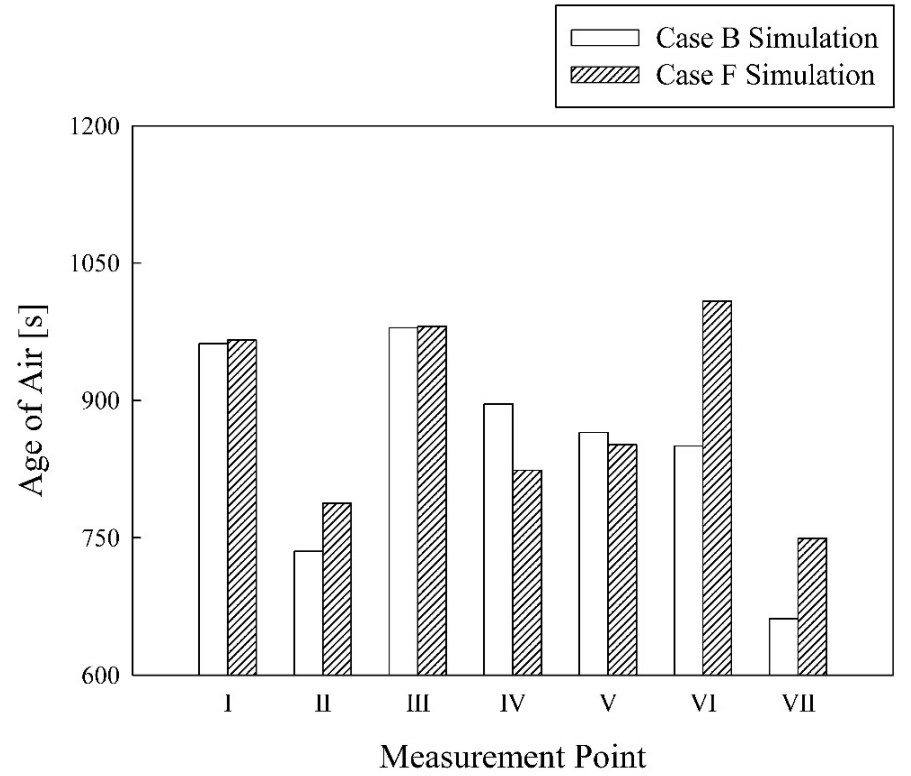

(b)

Fig. 8. Comparison of the age of air results between Case B and Case $F(a)$ experimental data (b) numerical results.

to place the ward bed near the ventilation inlets, in a hospital room where the SAC and curtains are used. However, when the SAC was operated, the air quality deteriorated at positions I, II and VII (increase of air age from experiment by $4.9 \%, 8.9 \%$ and $10.4 \%$, respectively; increase of air age from simulation by $0.4 \%, 7.2 \%$ and $13.3 \%$, respectively). This is largely due to the fact that the air flow in the areas surrounded by the curtains was stagnated. This implies that the air quality at the ward bed position can be worsened when the curtain is fully unfolded to isolate the ward bed under the operation of the SAC. Meanwhile, the air quality at positions IV and V was improved (decrease of air age from experiment by $3.4 \%$ and $0.7 \%$, respectively; decrease of air age from simulation by $8.1 \%$ and $1.5 \%$, respectively). This is because the clean air supplied from the VS inlets flowed under the curtain and then reached these positions $\mathrm{VI}$ and $\mathrm{V}$, and the air discharged from the SAC flowed along with this clean air from the VS inlets, owing to the large recirculation.

The overall indoor air quality could be improved by the simultaneous operation of the VS, SAC, and $A C$, but the air quality might deteriorate at positions where the flows caused by each device interfered with one another. Fig. 9 depicts the results of cases $C$ and $G$ and compares the air quality according to the operation of the SAC while the VS and the AC are operated. The personal curtains were not used in these cases. A comparison between Figs. 7 and 9 showed that the internal air quality was improved, and the age of air was generally lowered by the operation of the AC. In other words, the air ages determined from experiment and simulation decreased by $34.8 \%$ and $33.3 \%$, respectively, when the case $C$ was compared with the case $A$; they became lower by $31.4 \%$ and $34.4 \%$, respectively, when the case $\mathrm{G}$ was compared with the case $\mathrm{E}$. The installation of the AC in the vicinity of the ventilation outlets, where the introduction of fresh air was difficult, particularly resulted in a higher air quality at positions I, III, and VI compared to the results in Fig. 8. The air quality at positions VI and VII was improved by the simultaneous operation of the VS, SAC, and AC (decrease of air age from experiment by $3.6 \%$ and $7.1 \%$, respectively, decrease of air age from simulation by $0.8 \%$ and $11.6 \%$, respectively). Position VII particularly exhibited a significant air quality improvement because the air circulation became more active owing to the synergistic effect caused by the flow of the fresh air introduced through the ventilation inlets and the air flow caused by the SAC and the AC. However, the air quality at positions I, II, and IV deteriorated because the flow caused by the SAC and the AC interfered with each other (increase of air age from experiment by $1.7 \%$ and $0.8 \%$, respectively, increase of air age from simulation by $0.4 \%$ and $9.4 \%$, respectively). The air quality was improved in the region far from the SAC (positions VI and VII) while that was deteriorated in the region close to the SAC (positions I and II). However, the degree of improvement or deterioration of indoor air quality 


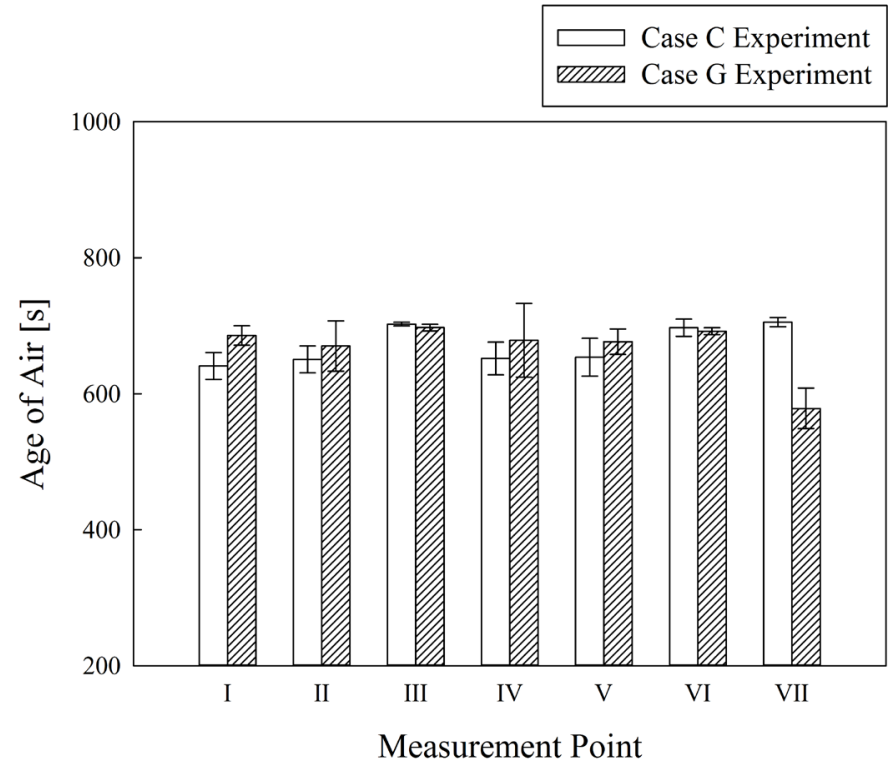

(a)

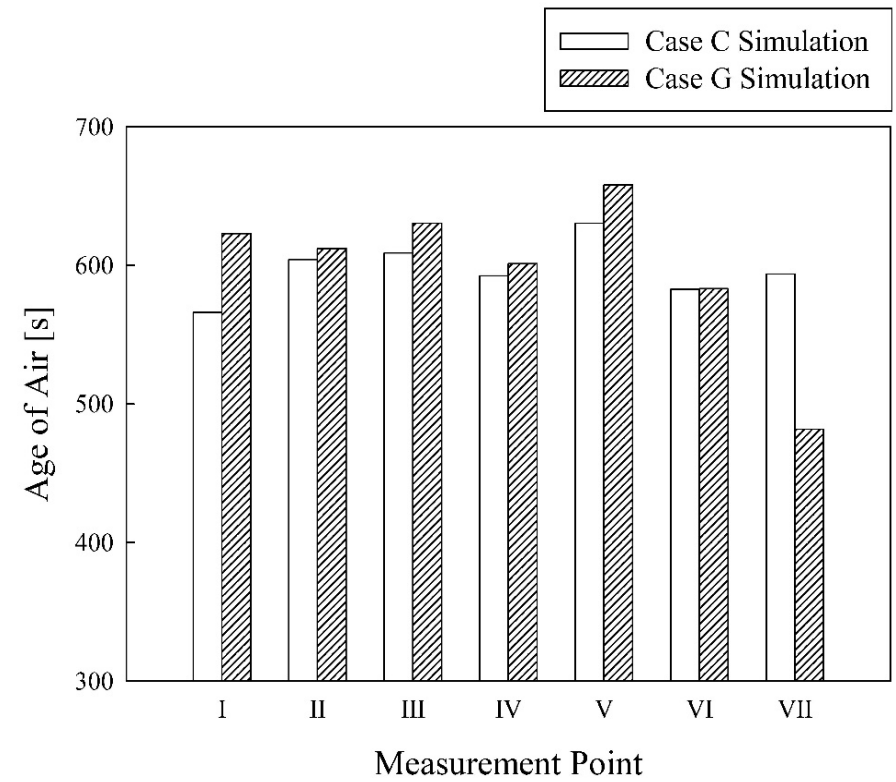

(b)

Fig. 9. Comparison of the age of air results between Case $C$ and Case $G(a)$ experimental data (b) numerical results.

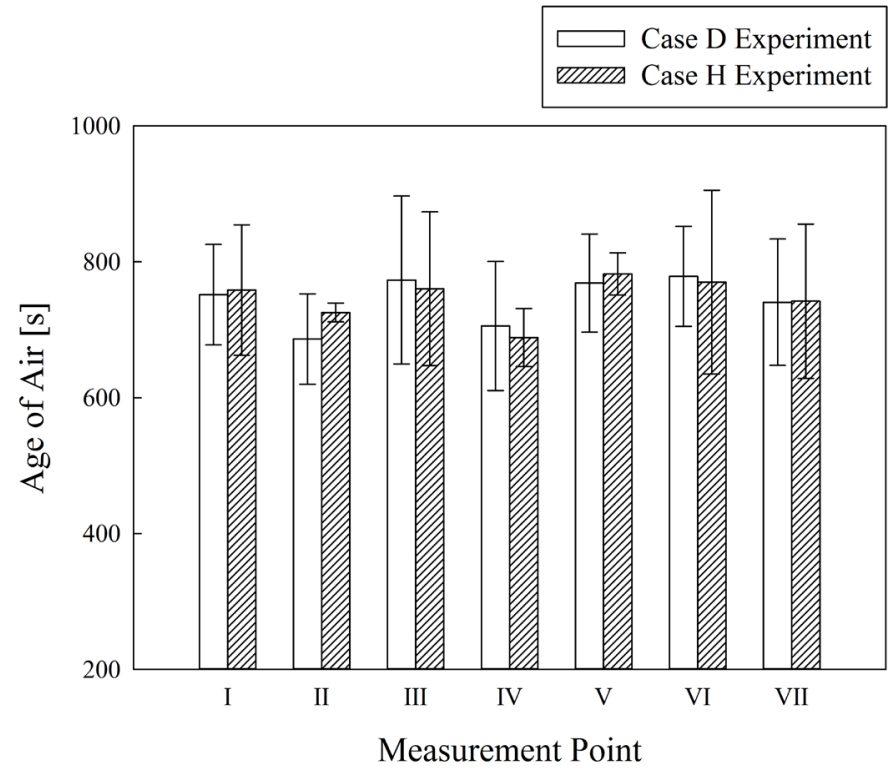

(a)

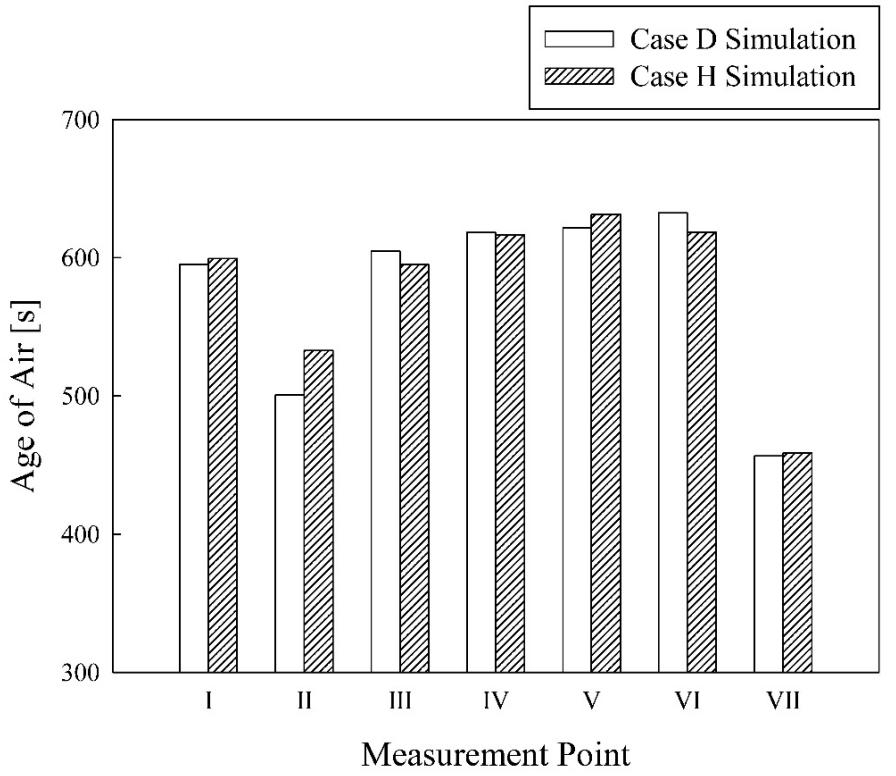

(b)

Fig. 10. Comparison of the age of air results between Case $D$ and Case $H(a)$ experimental data (b) numerical results.

by the SAC was small compared to that by the AC. Overall, it is recommended to use the AC to improve the air quality in the hospital wards.

Compared to the AC and the VS, the SAC was less influential on the improvement of indoor air quality, but it is recommended to place the ward beds in the region where the airflow generation devices including the SAC have a synergistic effect on the airflow circulation in a hospital ward. Fig. 10 shows the results of cases $\mathrm{D}$ and $\mathrm{H}$ and compares the indoor air quality according to the operation of the SAC while the VS and AC are operated, and every curtain was drawn. A comparison with Fig. 8, for which every curtain was drawn, but the AC was not operated, also confirmed that the overall age of air was lowered, and the indoor air quality was improved by the operation of the AC. In other words, the air ages from experiment and simulation decreased by $22.6 \%$ and $32.1 \%$, respectively, when the case $D$ was compared with the case $B$; they became 
lower by $26.6 \%$ and $28.2 \%$, respectively, when the case $\mathrm{H}$ was compared with the case $\mathrm{F}$. The age of air was relatively lower at positions II and VII located right under the ventilation inlets and relatively higher at positions I and VI located right under the ventilation outlets. Notably, the ages of air at positions III, IV, and V, which were the outside positions of the spaces surrounded by the curtains, were similar to those at positions I and VI located under the ventilation outlets. This finding was attributed to the air flow being stagnated by the large recirculation across positions III, IV, and V, caused by the AC in a situation where the fresh air introduced indoors through the ventilation inlets was not spread well because of the drawn curtains. The overall indoor air quality somewhat deteriorated when the SAC was additionally operated. In other words, this result occurred because of the interference between the flows caused by the AC and the SAC. The age of air at position I rose despite its close location to the AC because position I was also close to the SAC; thus, the flow of the fresh air from the AC was interrupted by the air flow discharged from the SAC, and had a difficulty reaching position I. These results confirmed that the areas with poor indoor air quality may be found if structures, such as curtains, that interfere with the air flow are present, or the air flows caused by the VS, AC, and SAC interfere with one another. Even when the curtains are drawn, the AC can improve the indoor air quality a lot.

\section{CONCLUSION}

This study investigated the effect of the flow caused by the operation of the four-way cassette system air conditioner (SAC) installed on the ceiling of the ward on the indoor air quality. Considering the situation of the ward, the changes in the age of air at seven positions were examined at the height ( $0.85 \mathrm{~m}$ from the floor) of the nose of a patient lying in the bed according to the operation of the SAC. The air flows from the outlets of the SAC in four directions could interfere with or contribute to the introduction of fresh air supplied from the ventilation system (VS) and/or the air cleaner (AC), depending on their positions in the ward.

It is recommended to place the ward beds in the regions under the VS inlets from where clean air is supplied, when the SAC is turned on. However, the clean air flow can be interrupted by the airflow blown by the SAC to lower the local age of air, in the region where the SAC is installed closer to the VS inlet. Therefore, if the SAC is operated along with the VS, it is more desirable to put the ward bed in the region under the VS inlet which is located farther from the SAC. If it is inevitable to place the ward beds in the regions under the VS outlets, the region closer to the SAC is preferred. When the ward curtains are fully unfolded to isolate each ward bed under the operation of the SAC along with the VS, the local air quality is worsened in the regions under the two VS inlets and the region under the VS outlet which is closer to the SAC, compared with the cases without using the ward curtains. By operating an AC in the area close to the VS outlets, along with the VS and the SAC, the local air quality can be enhanced not only in the regions under the VS outlets but also in the regions under the VS inlets. In other words, the AC can greatly reduce the average age of air in the ward, without regard to the use of the ward curtains.

The four-way cassette SAC affected the overall indoor air flow because it sucked in the indoor air through its large central area and discharged it in four directions from the ceiling. In this study, the SAC could act as a barrier to the supply of fresh air because the filter of the pre-filter grade with a very low efficiency was used in the SAC. The use of the SAC with the high-performance filter will significantly contribute to the air quality improvement in a ward. Therefore, the changes in the indoor air quality according to the filter grade used in the SAC must be studied. The supply of fresh air can be interrupted when the flow caused by the SAC interferes with that caused by the VS or AC; hence, further studies on determining the relative positions of flow-generating devices, such as the VS, AC, and SAC, as well as the positions of patient beds, are required to ensure the sufficient supply of fresh and clean air to the patients in wards.

\section{ACKNOWLEDGMENT}

This research was supported by the Basic Science Research Program through the National Research Foundation of Korea (NRF) funded by the Ministry of Science, ICT \& Future Planning (grant number: 2017R1A2B2006927). 
The authors declare that they have no known competing financial interests or personal relationships that could have appeared to influence the work reported in this paper.

\section{REFERENCES}

Adamu, Z.A., Price, A.D.F., Cook, M.J. (2012). Performance evaluation of natural ventilation strategies for hospital wards - A case study of Great Ormond Street Hospital. Build. Environ. 56, 211-222. https://doi.org/10.1016/j.buildenv.2012.03.011

Alajmi, A.F., Baddar, F.A., Bourisli, R.I. (2015). Thermal comfort assessment of an office building served by under-floor air distribution (UFAD) system - a case study. Build. Environ. 85, 153159. https://doi.org/10.1016/j.buildenv.2014.11.027

ANSI/ASHRAE/ASHE Standard 170-2008 (2013). Ventilation of Health Care Facilities, American Society of Heating, Refrigerating and Air-Conditioning Engineers, Inc., Atlanta.

ANSYS, Inc. (2009). Modeling Turbulence, in ANSYS FLUENT 12.0 User's Guide, ANSYS, Inc., Cecil Township, PA, Chap. 12.

Asif, A., Zeeshan, M., Jahanzaib, M. (2018). Indoor temperature, relative humidity and $\mathrm{CO}_{2}$ levels assessment in academic buildings with different heating, ventilation and air-conditioning systems. Build. Environ. 133, 83-90. https://doi.org/10.1016/j.buildenv.2018.01.042

Beggs, C.B. (2003). The airborne transmission of infection in hospital buildings: fact or fiction? Indoor Built Environ. 12, 9-18. https://doi.org/10.1177/1420326X03012001002

Chang, Y.C., Lee, H.W., Tseng, H.H. (2007). The formation of incense smoke. J. Aerosol Sci. 38, 39-51. https://doi.org/10.1016/j.jaerosci.2006.09.003

Chen, F., Chen, H., Xie, J., Shu, Z., Mao, J. (2011). Air distribution in room ventilated by fabric air dispersion system. Build. Environ. 46, 2121-2129. https://doi.org/10.1016/j.buildenv.2011.04. 016

Cheng, Y., Lin, Z. (2015). Technical feasibility of a stratum-ventilated room for multiple rows of occupants. Build. Environ. 94, 580-592. https://doi.org/10.1016/j.buildenv.2015.10.015

Gilkeson, C.A., Camargo-Valero, M.A., Pickin, L.E., Noakes, C.J. (2013). Measurement of ventilation and airborne infection risk in large naturally ventilated hospital wards. Build. Environ. 65, 3548. https://doi.org/10.1016/j.buildenv.2013.03.006

Han, C.W., Noh, K.C., Oh, M.D. (2005). Evaluation of thermal comfort and ventilation performance in the lecture room with ventilation system and two different air-conditioning systems: system air-conditioner or fan coil unit. Korean J. Air-Cond. Refrig. Eng. 17, 1079-1087. https://www.ko reascience.or.kr/article/JAKO200507523359436.page

Holmgren, H., Ljungström, E., Almstrand, A., Bake, B., Olin, A. (2010). Size distribution of exhaled particles in the range from 0.01 to $2.0 \mu \mathrm{m}$. J. Aerosol Sci. 41, 439-446. https://doi.org/10.101 6/j.jaerosci.2010.02.011

Jang, J.S., Noh, K.C., Oh, M.D. (2005). Study on the relationship between indoor $\mathrm{CO}_{2}$ concentration and local mean air-age in the lecture room with system air-conditioner and ventilation unit for cooling loads. Korean J. Air-Cond. Refrig. Eng. 17, 736-745. https://www.koreascience.or.kr/ar ticle/JAKO200504704355296.page

Ji, X., Le Bihan, O., Ramalho, O., Mandin, C., D’Anna, B., Martinon, L., Nicolas, M., Bard, D., Pairon, J.C. (2010). Characterization of particles emitted by incense burning in an experimental house. Indoor Air 20, 147-158. https://doi.org/10.1111/j.1600-0668.2009.00634.x

Jung, C.C., Wu, P.C., Tseng, C.H., Su, H.J. (2015). Indoor air quality varies with ventilation types and working areas in hospitals. Build. Environ. 85, 190-195. https://doi.org/10.1016/j.builden v.2014.11.026

Kong, M., Dang, T.Q., Zhang, J., Ezzat Khalifa, H. (2017). Micro-environmental control for efficient local cooling. Build. Environ. 118, 300-312. https://doi.org/10.1016/j.buildenv.2017.03.040

Lee, H., Awbi, H.B. (2004). Effect of internal partitioning on room air quality with mixing ventilation - statistical analysis. Renewable Energy 29, 1721-1732. https://doi.org/10.1016/j. renene.2003.12.023

Noh, J.H., Lee, J., Noh, K.C., Kim, Y.W., Yook, S.J. (2018). Effects of hospital ward curtains on 
ventilation in a four-bed hospital ward. Aerosol Air Qual. Res. 18, 2643-2653. https://doi.org/1 0.4209/aaqr.2017.11.0469

Noh, K.C., Oh, M.D. (2015). Variation of clean air delivery rate and effective air cleaning ratio of room air cleaning devices. Build. Environ. 84, 44-49. https://doi.org/10.1016/j.buildenv.2014. 10.031

Noh, K.C., Yook, S.J. (2016). Evaluation of clean air delivery rates and operating cost effectiveness for room air cleaner and ventilation system in a small lecture room. Energy Build. 119, 111118. https://doi.org/10.1016/j.enbuild.2016.03.027

Parra, M.T., Villafruela, J.M., Castro, F., Méndez, C. (2006). Numerical and experimental analysis of different ventilation systems in deep mines. Build. Environ. 41, 87-93. https://doi.org/10.10 16/j.buildenv.2005.01.002

Qian, H., Li, Y., Seto, W.H., Ching, P., Ching, W.H., Sun, H.Q. (2010). Natural ventilation for reducing airborne infection in hospitals. Build. Environ. 45, 559-565. https://doi.org/10.1016/ j.buildenv.2009.07.011

Rim, D., Novoselac, A. (2010). Ventilation effectiveness as an indicator of occupant exposure to particles from indoor sources. Build. Environ. 45, 1214-1224. https://doi.org/10.1016/j.builde nv.2009.11.004

See, S.W., Balasubramanian, R., Joshi, U.M. (2007). Physical characteristics of nanoparticles emitted from incense smoke. Sci. Technol. Adv. Mater. 8, 25-32. https://doi.org/10.1016/j.sta m.2006.11.016

Tung, Y.C., Shih, Y.C., Hu, S.C., Chang, Y.L. (2010). Experimental performance investigation of ventilation schemes in a private bathroom. Build. Environ. 45, 243-251. https://doi.org/10.10 16/j.buildenv.2009.06.007

Villafruela, J.M., Castro, F., José, J.F.S., Saint-Martin, J. (2013). Comparison of air change efficiency, contaminant removal effectiveness and infection risk as IAQ in isolation rooms. Energy Build. 57, 210-219. https://doi.org/10.1016/j.enbuild.2012.10.053

Wang, A., Zhang, Y., Sun, Y., Wang, X. (2008). Experimental study of ventilation effectiveness and air velocity distribution in an aircraft cabin mockup. Build. Environ. 43, 337-343. https://doi.org/10.1016/j.buildenv.2006.02.024

Wu, C., Ahmed, N.A. (2012). A novel mode of air supply for aircraft cabin ventilation. Build. Environ. 56, 47-56. https://doi.org/10.1016/j.buildenv.2012.02.025

Zhuang, R., Li, X., Tu, J. (2014). CFD study of the effects of furniture layout on indoor air quality under typical office ventilation schemes. Build. Simul. 7, 263-275. https://doi.org/10.1007/s1 2273-013-0144-5

Zuraimi, M.S., Nilsson, G.J., Magee, R.J. (2011). Removing indoor particles using portable air cleaners: Implications for residential infection transmission. Build. Environ. 46, 2512-2519. https://doi.org/10.1016/j.buildenv.2011.06.008 